\title{
Novel Solid State Nitric Oxide Sensor Using Siloxane-Poly(Oxypropylene) (PPO)
}

\author{
Rondinelli D. Herculano ${ }^{1}$, Carlos A. Brunello ${ }^{2}$, Jair P. Melo Jr. ${ }^{2}$, Mayler Martins ${ }^{3}$, Felipe A. Borges ${ }^{1}$, \\ Leila A. Chiavacci ${ }^{4}$, Carlos F. O. Graeff ${ }^{3}$ \\ ${ }^{1}$ Departamento de Ciências Biológicas, Faculdade de Ciências e Letras de Assis, Universidade Estadual Paulista "Júlio de Mesquita \\ Filho", Assis, Brazil; ${ }^{2}$ Departamento de Física, Faculdade de Filosofia, Ciências e Letras de Ribeirão Preto, Universidade de São \\ Paulo, Ribeirão Preto, Brazil; ${ }^{3}$ Departamento de Física, Faculdade de Ciências, Universidade Estadual Paulista "Júlio de Mesquita \\ Filho", Bauru, Brazil; ${ }^{4}$ Departamento de Fármacos e Medicamentos, Faculdade de Ciências Farmacêuticas, Universidade Estadual \\ Paulista "Júlio de Mesquita Filho", Araraquara, Brazil. \\ Email: rond@assis.unesp.br
}

Received September $12^{\text {th }}, 2013$; revised October $19^{\text {th }}, 2013$; accepted October $30^{\text {th }}, 2013$

Copyright (C) 2013 Rondinelli D. Herculano et al. This is an open access article distributed under the Creative Commons Attribution License, which permits unrestricted use, distribution, and reproduction in any medium, provided the original work is properly cited.

\begin{abstract}
In this paper, a novel solid state Nitric Oxide (NO) sensor made of a spin trap (iron(II)-diethyldithiocarbamate complex, FeDETC) encapsulated in a siloxane-poly(oxypropylene) (PPO) matrix was developed. Nitric oxide (NO), a free radical molecule, has numerous roles in various physiological functions, such as the regulation of blood pressure, immune response to bacterial infection, and nervous systems. Siloxane-polyether hybrid materials, for example siloxanepoly(oxypropylene) (PPO), are easy to prepare, transparent and flexible. The combination of all these characteristics in a unique material allows it to be used in several scientific and technological areas, including human health. NO radical is trapped in FeDETC, which allows its detection by electron paramagnetic resonance (EPR). FeDETC was added while PPO was a sol, which was then left in air for gelation. The novel sensor was dived directly into a solution of NO, when the NO-FeDETC complex was formed. Our results show that the novel sensor responds to NO, with similar sensitivity as previously published sensors. PPO sensors present a strong EPR signal and a high stability, keeping its signal for 45 days. We have studied ways to accelerate the NO release from the sensor, in order to study its potential as a drug delivery system. We observed an acceleration in NO release by using a modulated magnetic field of $40 \mathrm{G}$ at $100 \mathrm{kHz}$; as well as by UV irradiation. Thermal induced NO release was also tested by heating NO-FeDETC PPO up to $50^{\circ} \mathrm{C}$, with good results.
\end{abstract}

Keywords: Biomaterials; Nitric Oxide; PPO; Drug Delivery System

\section{Introduction}

Nitric oxide (NO) is a free radical with multiple physiological functions [1-3], and few decades ago, NO was just another toxic molecule, one of a lengthy list of environmental pollutants such as cigarette smoke and smog. Over the past few years, diverse lines of evidence have converged to show that this sometime toxic pollutant gas plays a fundamental role in numerous biological processes in the body [4]. NO is synthesized by three differentially gene-encoded nitric oxide synthase (NOS) enzymes $[4,5]$. It serves as a key signaling molecule in various physiological processes including vasodilatation, respiration, cell migration, immune response and apoptosis. Over recent years, it has become apparent that NO has important effects on bone cell function [6,7]. On the other hand, excessive and unregulated NO synthesis has been implicated as causal or contributing factor to various pathophysiological conditions including cancer [810]. Detection of NO presents a series of challenges since it is highly reactive, which means it has short lifetimes in living organisms, depending on the environment from milliseconds to minutes, before it reacts and consequently is found in low quantities in biological systems [11]. One way to measure NO is the use of spin traps like iron complexes with dithiocarbamates and porphyrins due to the affinity between $\mathrm{NO}$ and the iron complexes allowing the use of electron paramagnetic resonance (EPR) to radical detection. However, these complexes are unstable for long-term measurements. In previous works of our group [11-13], we proposed the encapsula- 
tion of iron(II)-diethyldithiocarbamate (FeDETC) in different matrixes for either the measurement of $\mathrm{NO}$ or its release.

In one of these matrixes, a NO sensor was made encapsulating FeDETC in a sol-gel matrix [14]. Sensors entrapped in gels offer numerous advantages when compared with liquid based systems: they are easier to manipulate, allow species detection and concentrations measurements with less contamination of the sample, can be used for continuous sensing and are normally more stable. In our case [14], the idea was to combine the specificity and high sensitivity of EPR, with the conveniences of working with a spin trap in the solid state. For EPR, measurement of special interest is the fact that solutions are in general hard to measure since liquids have high dielectric losses, or in other words they absorb microwaves, which limits severely the detection. EPR quartz liquid cells are necessary when liquids are to be measured by EPR, which are expensive and impose restrictions in what concerns the concentration of paramagnetic species. Therefore, entrapping the paramagnetic species in a solid is of great interest for EPR.

In another work $[12,13]$, natural rubber latex (NRL) was used as a matrix for the sustained and controlled delivery of NO. NRL is an important inductor of the healing process of wounds, being used in various biomedical applications like prosthetics and bone grafts [15-18]. Results showed that one can have sustained delivery of NO from NRL matrix for up to 350 hours. FTIR spectroscopy showed that NO/FeDETC when encapsulated in NRL has its properties and structure preserved [19].

In this work, we present a novel EPR NO sensor based on a siloxane-poly(oxypropylene) (PPO) matrix. The sensor was obtained by the spin trap iron(II)-diethyldithiocarbamate complex (FeDETC) encapsulated in a siloxane-poly(oxypropylene) PPO matrix. This same system is used for the sustained and controlled delivery of NO. This material is flexible, transparent and easily manipulated. We have tested different ways to do accelerated and controlled release of NO. The PPO-FeDETC system was exposed to ambient atmosphere (humidity $60 \%, 25^{\circ} \mathrm{C}$ ), ultraviolet, temperature at $50^{\circ} \mathrm{C}$, dark room, and magnetic field (amplitude modulation) of $40 \mathrm{G}$. The EPR signal of NO in the matrix was monitored as function of time.

\section{Materials and Methods}

First The PPO used in this work was obtained by sol-gel. All chemical reagents used are commercially available (Fluka, Aldrich). Succinctly, 3-isocyanatopropyltriethoxysilane (IsoTrEOS) and O,O'Bis(2-aminopropyl(polyoxypropylene)) in the molar ratio 2:1 were stirred together in tetrahydrofuran (THF) under reflux at $80^{\circ} \mathrm{C}$ for
$6 \mathrm{~h}$ to form the hybrid precursor 3(EtO)Si-(PPO)$\mathrm{Si}(\mathrm{OEt})_{3}[20,21]$.

The sol was obtained by mixing the precursor with the spin trap FeDETC in an ethanol solution containing $\mathrm{HCl}$ or $\mathrm{NH}_{4} \mathrm{~F}$. Hydrolysis was promoted by water addition followed by polycondensations reactions. This process was adopted for PPO polymers with molecular weight (MW) of 300 and $2000 \mathrm{~g} / \mathrm{mol}$ (labeled as $\mathrm{PPO}_{300}$ and $\mathrm{PPO}_{2000}$ ).

For the FeDETC solution, iron(III) chloride hexahydrate $\left(\mathrm{FeCl}_{3} \cdot 6 \mathrm{H}_{2} \mathrm{O}\right)$, dimethylformamide (DMF, $\mathrm{C}_{3} \mathrm{H}_{7} \mathrm{ON}$ ) and sodium dietyldithiocarbamate (DETC,

$\mathrm{C}_{5} \mathrm{H}_{10} \mathrm{NNaS}_{2} \cdot 3 \mathrm{H}_{2} \mathrm{O}$ ) were used. DMF and DETC were obtained from Acrós Organics (Belgium). The solution was prepared using $12 \mathrm{mg}$ of iron chloride and $20 \mathrm{mg}$ of DETC in $3 \mathrm{~mL}$ of DMF under magnetic agitation during 10 minutes. The entrapment of FeDETC in the matrix was obtained by mixing the PPO solution with FeDETC solution. After this, the solution was left in air for 2 day to complete the polymerization process resulting in a solid matrix. $\mathrm{NO}$ was generated in an aqueous solution by mixing $\mathrm{NaNO}_{2} 10 \mathrm{mM}(250 \mu \mathrm{L})$, deionized water $(750 \mu \mathrm{L})$ and $\mathrm{Na}_{2} \mathrm{~S}_{2} \mathrm{O}_{4}(145 \mathrm{mg})$ in an eppendorf tube of $1.5 \mathrm{~mL}$. In the presence of sodium dithionite $\left(\mathrm{Na}_{2} \mathrm{~S}_{2} \mathrm{O}_{4}\right)$ nitrite is reduced to NO. The saturated concentration of $\mathrm{NO}$ in this solution is $2.2 \mathrm{mM}$.

$$
\mathrm{NO}_{2}^{-}+\mathrm{Na}_{2} \mathrm{SO}_{4} \rightarrow \mathrm{NO}^{-}
$$

Electron Paramagnetic Resonance (EPR) experiments were done in a computer interfaced Varian E-4 X-band spectrometer at room temperature. For EPR measurements, the films were removed from the solution, dried and inserted in a quartz tube. For all samples the only signal observed was of the NO-FeDETC complex. To maximize signal to noise ratio various spectra were summed up, typically at least 10 . To avoid sample repositioning induced errors for the measurements following the EPR signal with time, the sample was kept inside the resonant cavity. A reference sample with a known and stable amount of spins was used before each measurement.

\section{Results and Discussion}

In recent years, the study of organic-inorganic nanocomposites became a mushrooming field of investigation due to the promising applications of these materials in optics, electronics, electrochemistry and biology [22-26]. These hybrids are considered as biphasic materials, the organic and inorganic phases being mixed at a nanometric scale. A family of hybrids, which recently attracted interest, consists of siloxane-polyether nanometer scale composites (Figure 1), in which the organic and inorganic phases are bonded by urea bridges, thus named ureasils [27]. These transparent materials were originally 


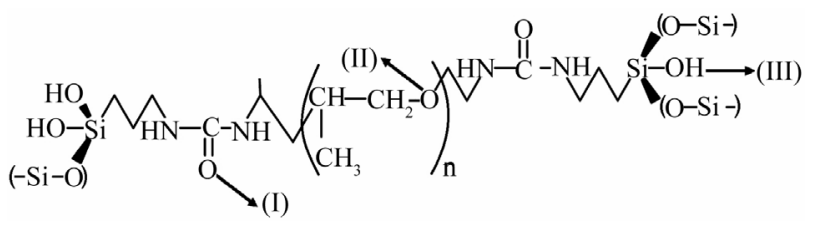

Figure 1. Siloxane-Poly(Oxypropylene) (PPO) monomer, with $\mathbf{n}=34$ for $\mathbf{P P O}_{2000}$ and $\mathbf{n}=\mathbf{5}$ for $\mathbf{P P O}_{300}$ [31] .

synthesized to be used in photochromic devices [28] as solid electrolytes $[29,30]$ because the covalent bonds between the polymer and the siloxane backbone hinder phase separation, preserving the stability of mechanical and thermal properties.

Gradzielski et al. [32] studied the aqueous aggregation behavior of several nonionic and ionic siloxane surfactants. They found micellar and lyotropic liquid crystal phases in siloxane surfactant/water systems similar to the phases found in hydrocarbon surfactant colloidal systems, although some of these siloxane surfactants have irregular branched structures.

We shall start by comparing the EPR signal of FeDETC:NO in different matrixes. [11-13]. In Figure 2 the EPR signal of the FeDETC:NO in a matrix of Latex and $\mathrm{SiOx}$ is shown. $\mathrm{SiOx}$ is a sol-gel matrix from siloxane. In the same figure the EPR signal of FeDETC:NO at different temperatures is also shown. Notice the similarities of the spectra measured in the matrixes at room temperature with the one in the solution measured at $77 \mathrm{~K}$.

In Figure 3, the EPR signal of the FeDETC:NO in different concentrations inside of the $\mathrm{PPO}_{300}$ matrix is shown. Notice that the signal increases as the FeDETC concentration is also increased. Another important parameter, which concerns the sensitivity of the NO delivery system, is the density of spin traps [14] incorporated into the PPO matrix. In this case, the function of FeDETC is to trap NO. As already mentioned, to maximize signal to noise ratio various spectra were summed up, typically at least 10 . All sensors were immersed in a saturated NO solution for $2 \mathrm{~h}$ prior to starting the measurements. These spectra were taken after leaving the sample in the dark for $24 \mathrm{~h}$ after immersion in the NO solution. Figure 3(a) shows the EPR signal amplitude as a function of FeDETC concentration for the PPO matrix. The experimental data in Figure 3(b) were fitted using an exponential decay function.

In Figure 4, the $\mathrm{PPO}_{300}$ sensor was immersed in a 2.5 $\mathrm{mM}$ NO solution for 2 hours. The EPR signal amplitude just after the sensor was taken from the NO solution is plotted as a function of time in different conditions: 1) left in the dark at room temperature, 2) under ultraviolet illumination, 3) left at $50^{\circ} \mathrm{C}$ and 4) dark room. As can be seen, the signal decreases with time until it vanishes for temperature at $50^{\circ} \mathrm{C}$ and dark room. However, the EPR signal increase for samples preserved at room tempera-

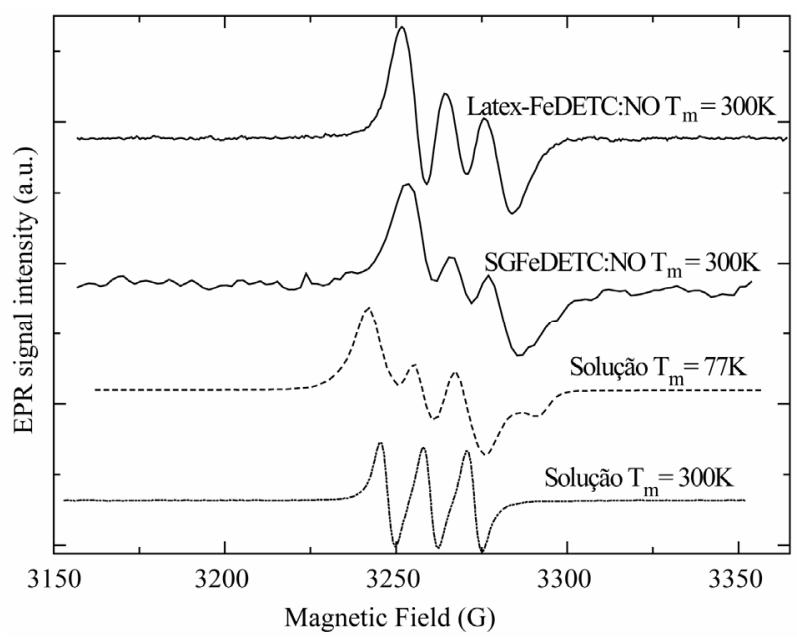

Figure 2. Typical EPR spectra from FeDETC:NO in solution and inside the Latex matrix, and SiOx matrix. For the spectra in solution (dashed lines) the measurement temperatures were $300 \mathrm{~K}$ and $77 \mathrm{~K}$ [13].

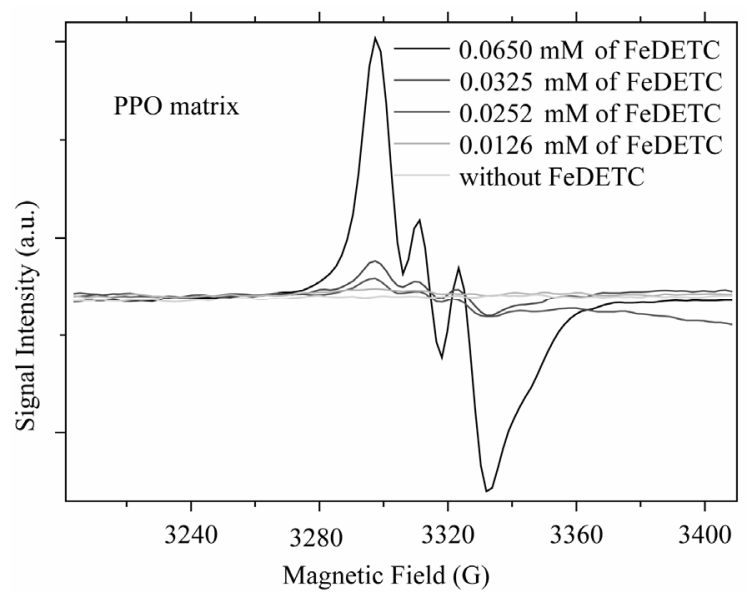

(a)

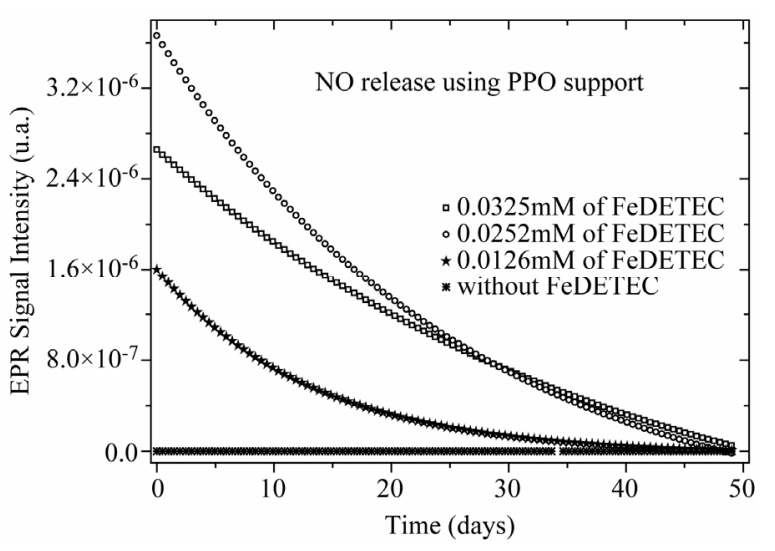

(b)

Figure 3. EPR signal from FeDETC:NO of PPO matrix as a function of FeDETC concentration: (a) Amplitude intensity; (b) Amplitude as a function of time. Notice that FeDETC:NO signal amplitudes are essentially dependent of FeDETC concentration. 


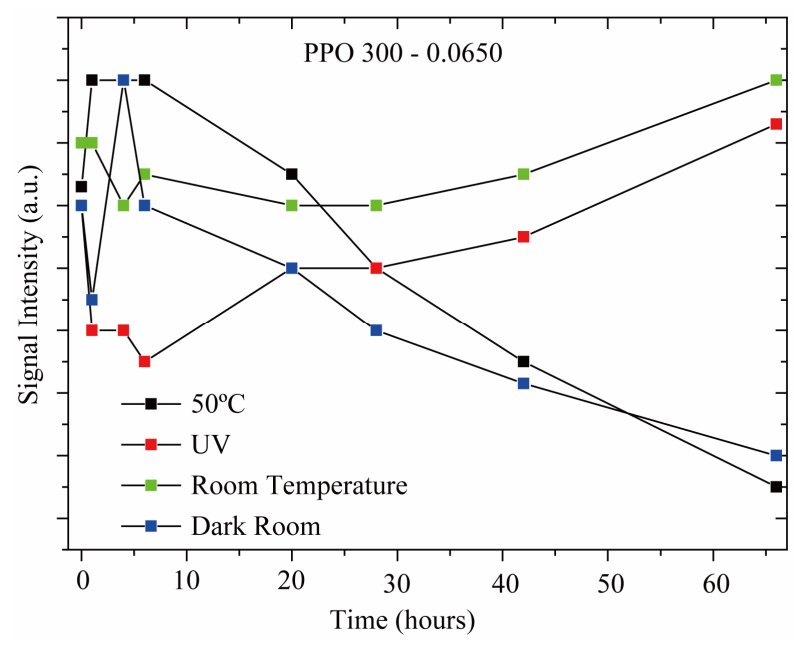

Figure 4. EPR signal intensity of $\mathbf{P P O}_{300}$ sensor as a function of time.

ture and UV.

In Figure 5, the EPR signal amplitude just after the $\mathrm{PPO}_{2000}$ sensor was taken from the NO solution is plotted as a function of time in different conditions: 1) UV, 2) dark room, 3) temperature at $50^{\circ} \mathrm{C}$ and 4) magnetic field (Amplitude Modulation) of $40 \mathrm{G}$. As can be seen, the signal decreases with time until it vanishes all samples.

In Figures 4 and 5, we observed that EPR signal amplitudes $\left(\mathrm{PPO}_{300}\right.$ and $\left.\mathrm{PPO}_{2000}\right)$ increase with the FeDETC quantify, but non-linearly. We demonstrated that diethyldithiocarbamates is presence in PPO support. FeDETC:NO signal amplitudes are essentially dependent of FeDETC concentration [12,14]. In addition, the PPO sensors present a stronger EPR signal and highest stability, keeping the NO signal intensity for more than 40 days. The ultraviolet radiation induces an increase in EPR signal in both matrixes. Moreover, modulated magnetic field of $40 \mathrm{G}$ at $100 \mathrm{kHz}$, as well exposing the $\mathrm{PPO}_{2000}$ sensor to a temperature at $50^{\circ} \mathrm{C}$, accelerated the NO release from the sensor, i.e.; field magnetic induced release of NO has potential application as a drug delivery system. The acceleration in the NO release is due the hyperthermia magnetic.

Kumar \& Mohammad [33] presented a case for broadening the meaning of the term "hyperthermia" by including thermotherapy as well as magnetically modulated controlled drug delivery. They provided a classification for controlled drug delivery using hyperthermia: The highlight of this work was to portray potential opportunities for the combination of hyperthermia-based therapy and controlled drug release paradigms-towards successful application in personalized medicine.

Lien \& Wu [34] synthesized the multifunctional magnetic nanoparticles $\left(\mathrm{SiO}_{2} / \mathrm{Fe}_{3} \mathrm{O}_{4}\right)$ containing thermosensitive polymers (PNIPAM, poly(N-isopropylacrylamide), generating thermosensitive and magnetic properties of

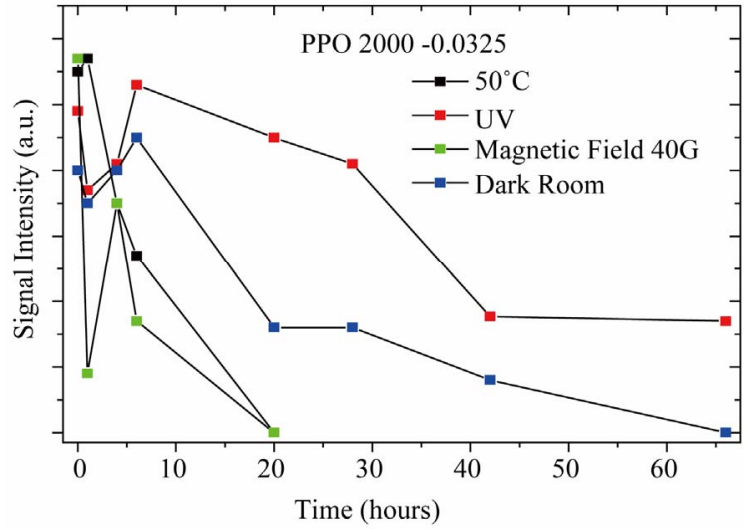

Figure 5. EPR signal intensity of $\mathbf{P P O}_{2000}$ sensor as a function of time.

nanocomposites. The magnetic properties of $\mathrm{SiO}_{2} / \mathrm{Fe}_{3} \mathrm{O}_{4}$ nanoparticles show superparamagnetic behavior. They observed that for thermosensitivity analysis, the phase transition temperatures of multifunctional nanoparticles measured using DSC was at around $34^{\circ} \mathrm{C}-36^{\circ} \mathrm{C}$.

Kim et al. [35] synthesized and characterized multifunctional chitosan- $\mathrm{MnFe}_{2} \mathrm{O}_{4}$ MNPs for hyperthermia and drug release behavior. They observed that these nanoparticles display significant heating for hyperthermia applications (which when adds to their already-reported use in MRI).

Already, others works have shown the magnetic field influence in drug delivery. Souza et al. [36] showed the influence of magnetic nanoparticles $\left(\mathrm{SiO}_{2} / \mathrm{Fe}_{3} \mathrm{O}_{4}\right)$ on drug release kinetics with cisplatin, carboplatin, and atenolol under in vitro conditions in the absence and in the presence of an external magnetic field $(0.25 \mathrm{~T})$ by using $\mathrm{NdFeB}$ permanent magnet. The constant external magnetic field did not affect drug release significantly. The low-frequency alternating magnetic field had a large influence on the cisplatin release profile.

Chen et al. [37] (2008) grafted doxorubincin (DOX, anticancer agent) into surface of the core-shell nanoparticles $\left(\mathrm{Fe}_{3} \mathrm{O}_{4} / \mathrm{SiO}_{2}\right)$. They showed that DOX-grafted $\mathrm{Fe}_{3} \mathrm{O}_{4} / \mathrm{SiO}_{2}$ core-shell structure nanoparticles presented a superparamagnetic property with a saturation magnetization value of $49.3 \mathrm{emu} / \mathrm{g}$, indicating a great potential application in the treatment of cancer using magnetic targeting drug-delivery technology.

Souza et al. [38] (2008) showed that the magnetite nanoparticles $\left(\mathrm{Fe}_{3} \mathrm{O}_{4}\right)$ are completely coated by wellordered mesoporous silica $\left(\mathrm{SiO}_{2}\right)$ with free pores and stable $(\sim 8 \mathrm{~nm}$ thick) pore walls, and that the structural and magnetic properties of the $\mathrm{Fe}_{3} \mathrm{O}_{4}$ nanoparticles are preserved in the applied synthesis route.

PPOs associated to FeDETC-NO are easy to manipulate, allow species detection and concentrations measurements with few sample contamination. These charac- 
teristics indicate that PPO matrix may be a good choice for a NO delivery system, with superior mechanical properties [11-13]. The samples are very stable: the signal amplitude of NO could be detected even after 40 days exposed to ambient atmosphere. As NO is an early mediator of the inflammatory process associated to tissue regeneration presented interesting biological properties.

\section{Conclusion}

We propose a novel NO delivery system made of a spin trap (iron(II)-diethyldithiocarbamate complex, FeDETC) encapsulated in a PPO matrix. The rate release of NO in this system was observed by EPR, exposing the sample to ambient atmosphere. The results indicate that it is possible for NO to release for 40 days. Moreover, a system with modulated magnetic field of $40 \mathrm{G}$ at $100 \mathrm{kHz}$ in PPO sensor to a temperature at $50^{\circ} \mathrm{C}$, accelerated the NO release from the sensor, i.e. field magnetic, and induced release of NO, has potential application as a drug delivery system. The acceleration in the NO release is due to the hyperthermia magnetic. In addition, the matrix is flexible, transparent and easily manipulated.

\section{Acknowledgements}

We are grateful to J. L. Aziani for technical support. This work received financial support from FAPESP, CNPq and CAPES.

\section{REFERENCES}

[1] S. Nagassaki, R. D. Herculano, C. F. O. Graeff and J. E. Tanus-Santos, "eNOS T-786C Polymorphism Affects Atorvastatin-Induced Changes in Erythrocyte Membrane Fluidity," European Journal of Clinical Pharmacology, Vol. 65, No. 4, 2009, pp. 385-392.

http://dx.doi.org/10.1007/s00228-008-0602-7

[2] S. Archer, "Measurement of Nitric Oxide in Biological Models," FASEB Journal, Vol. 7, No. 2, 1993, pp. 349360.

[3] S. Moncada, R. M. J. Palmer and E. A. Higgs, "Nitric Oxide: Physiology, Pathophysiology and Pharmacology," Pharmacological Reviews, Vol. 43, No. 2, 1991, pp. 109142.

[4] P. Muriel and G. Sandoval, "Nitric Oxide and Peroxynitrite Anion Modulate Liver Plasma Membrane Fluidity and $\mathrm{Na}(+) / \mathrm{K}(+)$-Atpase Activity," Nitric Oxide, Vol. 4, No. 4, 2000, pp. 333-342.

http://dx.doi.org/10.1006/niox.2000.0285

[5] D. D. Rees, R. M. Palmer and S. Moncada, "Role of Endothelium-Derived Nitric Oxide in the Regulation of Blood Pressure," Proceedings of the National Academy of Sciences USA, Vol. 86, No. 9, 1989, pp. 3375-3378. http://dx.doi.org/10.1073/pnas.86.9.3375

[6] R. J. van't Hof and S. H. Ralston, "Nitric Oxide and Bone," Immunology, Vol. 103, No. 3, 2001, pp. 255-261. http://dx.doi.org/10.1046/j.1365-2567.2001.01261.x

[7] P. Collin-Osdoby, G. A. Nickols and P. Osdoby, "Bone Cell Function, Regulation, and Communication: A Role for Nitric Oxide," Journal of Cellular Biochemistry, Vol. 57, No. 3, 1995, pp. 399-408. http://dx.doi.org/10.1002/jcb.240570305

[8] U. Förstermann and T. Münzel, "Endothelial Nitric Oxide Synthase in Vascular Disease from Marvel to Menace," Circulation, Vol. 113, No. 13, 2006, pp. 1708-1714. http://dx.doi.org/10.1161/CIRCULATIONAHA.105.6025 $\underline{32}$

[9] U. Förstermann, E. I. Closs, J. S. Pollock, M. Nakane, P. Schwarz, I. Gath and H. Kleinert, "Nitric Oxide Synthase Isozymes: Characterization, Purification, Molecular Cloning, and Functions," Hypertension, Vol. 23, No. 6, 1994, pp. 1121-1131.

[10] C. S. Raman, H. Li, P. Martasek, V. Kral, B. S. Masters and T. L. Poulos, "Crystal Structure of Constitutive Endothelial Nitric Oxide Synthase: A Paradigm for Pterin Function Involving a Novel Metal Center," Cell, Vol. 95, No. 7, 1998, pp. 939-950. http://dx.doi.org/10.1016/S0092-8674(00)81718-3

[11] R. D. Herculano, C. A. Brunello and C. F. O. Graeff, "Solid State Nitric Oxide Sensor Using a Latex Rubber Matrix," Macromolecular Symposia, Vol. 245-246, No. 1, 2006, pp. 529-532.

http://dx.doi.org/10.1002/masy.200651376

[12] R. D. Herculano, C. A. Brunello and C. F. O. Graeff, "Optimization of a Novel Nitric Oxide Sensor Using a Latex Rubber Matrix," Journal of Applied Sciences, Vol. 7, No. 23, 2007, pp.3801-3805.

http://dx.doi.org/10.3923/jas.2007.3801.3805

[13] R. D. Herculano, L. C. Tzu, C. P. Silva, C. A. Brunello, A. A. A. Queiroz, A. Kinoshita and C. F. O. Graeff, "Nitric Oxide Release Using Natural Rubber Latex as Matrix," Materials Research, Vol. 14, No. 3, 2011, pp. 355-359. http://dx.doi.org/10.1590/S1516-14392011005000055

[14] J. P. de Melo-Jr, J. C. Biazotto, C. A. Brunello and C. F. O. Graeff, "Solid State Nitric Oxide Sensor Prepared by Sol-Gel Entrapment of Iron(III) Diethyldithiocarbamate in a Silica Matrix," Journal of Non-Crystalline Solids, Vol. 348, 2004, pp. 235-239. http://dx.doi.org/10.1016/j.jnoncrysol.2004.08.175

[15] C. Ereno, S. A. C. Guimarães, S. Pasetto, R. D. Herculano, C. P. Silva, C. F. O. Graeff, O. Tavano, O. Baffa and A. Kinoshita, "Latex Use as an Occlusive Membrane for Guided Bone Regeneration," Journal of Biomedical Materials Research Part A, Vol. 95A, No. 3, 2010, pp. 932-939. http://dx.doi.org/10.1002/jbm.a.32919

[16] R. D. Herculano, A. A. A. Queiroz, A. Kinoshita, O. N. Oliveira Jr. and C. F. O. Graeff, "On the Release of Metronidazole from Natural Rubber Latex Membranes," Material Science Engineering C, Vol. 31, No. 2, 2011, pp. 272-275. http://dx.doi.org/10.1016/j.msec.2010.09.007

[17] M. Ferreira, R. J. Mendonça, J. Coutinho-Netto and M. Mulato, "Angiogenic Properties of Natural Rubber Latex Biomembranes and the Serum Fraction of Hevea Brasiliensis," Brazilian Journal of Physics, Vol. 39, No. 3, 2009, pp. 564-596. 
http://dx.doi.org/10.1590/S0103-97332009000500010

[18] F. Mrué, J. Coutinho-Netto, R. Ceneviva, J. J. Lachat, J. A. Thomazini and H. Tambelini, "Evaluation of the Biocompatibility of a New Biomembrane," Materials Research, Vol. 7, No. 2, 2004, pp. 277-283. http://dx.doi.org/10.1590/S1516-14392004000200010

[19] J. A. Thomazini, F. Mrué, J. Coutinho-Netto, J. J. Lachat, R. Ceneviva and A. C. Zborowski, "Morphological and Biochemical Characterization of a Prosthesis Manufactured from Natural Latex of Hevea Brasiliensis for Medical Utilization,” Acta Microscópica, Vol. 6, No. B, 1997, pp. 798-799.

[20] J. A. Chaker, K. Dahmouche, C. V. Santilli, S. H. Pulcinelli and A. Craievich, "Gelation and Drying of Weakly Bonded Silica-PPO Nanocomposites," Journal of Applied Crystallography, Vol. 36, No. 1-3, 2003, pp. 689-693.

[21] J. A. Chaker, K. Dahmouche, C. V. Santilli, S. H. Pulcinelli, V. Briois and P. Judeinstein, "Structure and Electrical Properties of Potassium-Doped Siloxane-Poly(Oxypropylene) Ormolytes," Journal of Sol-Gel Science and Technology, Vol. 26, No. 1-3, 2003, pp. 1075-1080. http://dx.doi.org/10.1023/A:1020702606334

[22] L. A. Chiavacci, K. Dahmouche, N. J. O Silva, L. D. Carlos, V. S. Amaral, V. Z. Bermudez, S. H. Pulcineli, C. V. Santilli, V. Briois and A. F. Craievich, "Effect of Presence of an Acid Catalyst on Structure and Properties of Iron-Doped Siloxane-Polyoxyethylene Nanocomposites Prepared by Sol-Gel," Journal of Non-Crystalline Solids 10, Vol. 345-346, 2004, pp. 585-590.

[23] B. M. Novak, "Hybrid Nanocomposite Materials-Between Inorganic Glasses and Organic Polymers," Advanced Materials, Vol. 5, No. 6, 2004, pp. 422-433. http://dx.doi.org/10.1002/adma.19930050603

[24] C. Sanchez, F. Ribot and B. Lebeau, "Molecular Design of Hybrid Organic-Inorganic Nanocomposites Synthesized via Sol-Gel Chemistry," Journal of Materials Chemistry, Vol. 9, 1999, pp. 35-44. http://dx.doi.org/10.1039/a805538f

[25] "Sol-Gel Optics, Series I to VIII, Proc. SPIE," In: J. D. Mackenzie, D. Stauffer, A. Coniglio and M Adam, Eds., Advances in Polymer Science, Vol. 44, 1992, pp. 103158.

[26] V. H. V. Sarmento, K. Dahmouche, S. H. Pulcinelli and C. V. Santilli, "Effect of Lithium Doping on the Evolution of Rheological and Structural Properties during Gelation of Siloxane-Poly(Oxypropylene) Nanocomposites," Journal of Materials Chemistry, Vol. 15, 2005, pp. 3962-3972. http://dx.doi.org/10.1039/b505462c

[27] K. Dahmouche, P. H. De Souza, T. J. Bonagamba, H. Paneppucci, P. Judeinstein, S. H. Pulcinelli and C. V. Santilli, "Investigation of New Ion Conducting Ormolytes Silica-Polypropyleneglycol," Journal of Sol-Gel Science and Technology, Vol. 13, No. 1-3, 1998, pp. 909-913. http://dx.doi.org/10.1023/A:1008627424438

[28] K. Dahmouche, M. Atik, N. C. Mello, T. J. Bonagamba, H. Panepucci, P. Judeinstein and M. A. Aegerter, "New Li+ Ion-Conducting Ormolytes: Fundamental and Technological Applications," Solar Energy Materials and So- lar Cells, Vol. 54, No. 1, 1998, pp. 1-8. http://dx.doi.org/10.1016/S0927-0248(97)00217-1

[29] V. Z. Bermudeza, L. D. Carlosb, M. C. Duartea, M. M. Silvac, C. J. R. Silvac, M. J. Smithc, M. Assunção and L. Alcácerd, "A Novel Class of Luminescent Polymers Obtained by the Sol-Gel Approach," Journal of Alloys and Compounds, Vol. 275-277, 1998, pp. 21-26. http://dx.doi.org/10.1016/S0925-8388(98)00266-7

[30] L. A. Chiavaccia, K. Dahmouchea, N. J. O. Silvab, L. D. Carlosb, V. S. Amaralb, V. Z. Bermudezc, S. H. Pulcinellia, C. V. Santillia, V. Brioisd and A. F. Craievich, "Effect of Presence of an Acid Catalyst on Structure and Properties of Iron-Doped Siloxane-Polyoxyethylene Nanocomposites Prepared by Sol-Gel," Journal of NonCrystalline Solids 10, Vol. 345-346, 2004, pp. 585-590.

[31] V. H. V. Sarmento, K. Dahmouche, C. V. Santilli and S. H. Pulcinelli, "Gelation of Siloxane-Poly(Oxypropylene) Composites," Journal of Non-Crystalline Solids, Vol. 304, No. 1-3, 2002, pp. 134-142. http://dx.doi.org/10.1016/S0022-3093(02)01015-3

[32] M. Gradzielski, H. Hoffmann, P. Robisch, W. Ulbricht and B. Grüning, "The Aggregation Behaviour of Silicone Surfactants in Aqueous Solutions," Tensile Surfactant Detergent, Vol. 27, No. 6, 1990, pp. 366-379.

[33] C. S. S. R. Kumar and F. Mohammad, "Magnetic Nanomaterials for Hyperthermia-Based Therapy and Controlled Drug Delivery," Advanced Drug Delivery Reviews, Vol. 63, No.9, 2011, pp. 789-808. http://dx.doi.org/10.1016/j.addr.2011.03.008

[34] Y. H. Lien and T. M. Wu, "Preparation and Characterization of Thermosensitive Polymers Grafted Onto SilicaCoated Iron Oxide Nanoparticles," Journal of Colloid and Interface Science, Vol. 326, No. 2, 2008, pp. 517-521. http://dx.doi.org/10.1016/j.jcis.2008.06.020

[35] D. H. Kim, D. E. Nikles and C. S. Brazel, "Synthesis and Characterization of Multifunctional Chitosan- $\mathrm{MnFe}_{2} \mathrm{O}_{4}$ Nanoparticles for Magnetic Hyperthermia and Drug Delivery," Materials, Vol. 3, No. 7, 2010, pp. 4051-4065. http://dx.doi.org/10.3390/ma3074051

[36] K. C. Souza, J. D. Ardisson and E. M. Sousa, "Study of Mesoporous Silica/Magnetite Systems in Drug Controlled Release," Journal of Materials Science: Materials in Medicine, Vol. 20, No. 2, 2009, pp. 507-512. http://dx.doi.org/10.1007/s10856-008-3592-1

[37] F. H. Chen, Q. Gao and J. Z. Ni, "The Grafting and Release Behavior of Doxorubincin from $\mathrm{Fe}_{3} \mathrm{O}_{4} / \mathrm{SiO}_{2}$ CoreShell Structure Nanoparticles via an Acid Cleaving Amide Bond: The Potential for Magnetic Targeting Drug Delivery," Nanotechnology, Vol. 19, No. 16, 2008, pp. 165103-165111. http://dx.doi.org/10.1088/0957-4484/19/16/165103

[38] K. C. Souza, G. Salazar-Alvarez, J. D. Ardisson, W. A. A. Macedo and E. M. B. Sousa, "Mesoporous Silica-Magnetite Nanocomposite Synthesized by Using a Neutral Surfactant," Nanotechnology, Vol. 19, No. 18, 2008, pp. 185603-185609. http://dx.doi.org/10.1088/0957-4484/19/18/185603 